\title{
openheart Higher risk of major adverse cardiac events after acute myocardial infarction in patients with schizophrenia
}

\author{
Rubina Attar (D) , ${ }^{1,2}$ Axel Wester, ${ }^{1}$ Sasha Koul, ${ }^{3}$ Svend Eggert, ${ }^{2}$ \\ Christoffer Polcwiartek, ${ }^{2}$ Tomas Jernberg, ${ }^{4}$ David Erlinge, ${ }^{1}$ Pontus Andell (D) ${ }^{1,5}$
}

To cite: Attar R, Wester A, Koul S, et al. Higher risk of major adverse cardiac events after acute myocardial infarction in patients with schizophrenia. Open Heart 2020;7:e001286. doi:10.1136/ openhrt-2020-001286

Parts of the results have previously been presented in poster format at the European Society of Cardiology Congress.

Received 6 March 2020

Revised 29 June 2020

Accepted 3 August 2020

Check for updates

(c) Author(s) (or their employer(s)) 2020. Re-use permitted under CC BY-NC. No commercial re-use. See rights and permissions. Published by BMJ.

${ }^{1}$ Cardiology and Clinical Sciences, Lund University, Lund, Sweden

${ }^{2}$ Cardiology and Clinical Medicine, Aalborg University Hospital, Aalborg, Denmark

${ }^{3}$ Cardiology, Lund University, Lund, Sweden

${ }^{4}$ Department of Clinical Sciences, Danderyd University Hospital, Karolinska Institutet, Stockholm, Sweden

${ }^{5}$ Unit of Cardiology, Department of medicine and Heart and Vascular Division, Karolinska Institute, Stockholm, Sweden

Correspondence to Dr Rubina Attar; r.attar@rn.dk

\section{ABSTRACT}

Background Patients with schizophrenia are a high-risk population due to higher prevalences of cardiovascular risk factors and comorbidities that contribute to shorter life expectancy.

Purpose To investigate patients with and without schizophrenia experiencing an acute myocardial infarction (AMI) in relation to guideline recommended in-hospital management, discharge medications and 5-year major adverse cardiac events (MACE: composite of all-cause mortality, rehospitalisation for reinfarction, stroke or heart failure).

Methods All patients with schizophrenia who experienced AMI during 2000-2018 were identified $(n=1008)$ from the nationwide Swedish Web-system for Enhancement and Development of Evidence-based care in Heart disease Evaluated According to Recommended Therapies registry and compared with $A M I$ patients without schizophrenia $(n=285325)$. Kaplan-Meier survival curves and multivariable Cox regression models were used to compare the populations.

Results Patients with schizophrenia presented with AMl approximately 10 years earlier (median age 64 vs 73 years), and had higher prevalences of diabetes, heart failure and chronic obstructive pulmonary disease. They were less likely to be invasively investigated or discharged with aspirin, P2Y12 inhibitors, ACE inhibitors/angiotensin II receptor blockers, beta-blockers and statins (all $p<0.005$ ). AMI patients with schizophrenia had higher adjusted risk of MACE (aHR=2.05, 95\% Cl 1.63 to 2.58), mortality (aHR=2.38, 95\% Cl 1.84 to 3.09) and hospitalisation for heart failure (aHR=1.39, 95\% $\mathrm{Cl} 1.04$ to 1.86$)$ compared with AMI patients without schizophrenia.

Conclusion Patients with schizophrenia experienced an AMI almost 10 years earlier than patients without schizophrenia. They less often underwent invasive procedures and were less likely to be treated with guideline recommended medications at discharge, and had more than doubled risk of MACE and allcause mortality. Improved primary and secondary preventive measures, including adherence to guideline recommendations, are warranted and may improve outcome.

\section{INTRODUCTION}

Patients with schizophrenia constitute a high-risk population partially attributed

\section{Key questions}

What is already known about this subject?

- Patients with schizophrenia are a high-risk population with increased mortality, mainly attributed to cardiovascular diseases because of highly prevalent modifiable cardiovascular risk factors.

What does this study add?

- A nationwide analysis of the major adverse cardiac events after acute myocardial infarction (AMI) in a population with schizophrenia, using the Swedish Web-system for Enhancement and Development of Evidence-based care in Heart disease Evaluated According to Recommended Therapies (SWEDEHEART) registry. Our study indicates that the use of guideline recommended therapy in this population following discharge is lower than in patients without schizophrenia, contributing to the worse outcome seen in this population.

How might this impact on clinical practice?

- Our results highlight the extent of risk patients with schizophrenia have after an AMI and that they are treated to a lower extent with guideline-based medications. We argue that a multidisciplinary approach should be considered to improve risk factor control, guideline-based treatment and outcome in this high-risk population.

to increased prevalence of cardiovascular risk factors such as diabetes, hypertension, metabolic syndrome, smoking as well as unhealthy eating habits and low physical activity compared with the general population. ${ }^{1-3}$ Cardiovascular disease is the leading cause of death in patients with schizophrenia, accounting for far more deaths than suicide. ${ }^{4}$ Schizophrenia is accompanied by a twofold to threefold increased risk of the two most frequent cardiovascular death causes, coronary heart disease (CHD) and cerebrovascular disease, compared with the general population and half of the deaths from CHD are caused by acute myocardial infarctions (AMI).${ }^{56}$ Notably, several studies 
have concluded that patients with schizophrenia receive suboptimal preventive and cardiac care despite being at such high risk. ${ }^{7-10}$ Furthermore, the use of atypical antipsychotic medications also contributes to the development of metabolic syndrome and consequently increases the risk of cardiovascular disease. ${ }^{11}$

Despite the increased interest in this topic, there is a lack of comprehensive studies of the schizophrenia population with regards to comorbidities, in-hospital treatment, discharge medications and outcomes following AMI in contemporary nationwide study samples. The aim of this study was therefore to describe characteristics of, and the use of guideline recommended secondary preventive medications at discharge and 5-year risk of major adverse cardiac events (MACE: all-cause mortality, rehospitalisation for AMI, hospitalisation for stroke or heart failure) in patients with and without schizophrenia experiencing an AMI.

\section{METHODS}

\section{Study sample}

This nationwide observational follow-up study included all patients aged $\geq 18$ years with a ST-segment elevation MI (STEMI) or non-STEMI (NSTEMI) diagnosis between 1 January 2000 and 29 May 2018 and registered in the Swedish Web-system for Enhancement and Development of Evidence-based care in Heart disease Evaluated According to Recommended Therapies (SWEDEHEART) registry. The patient cohort was divided into patients with and without a schizophrenia diagnosis. The STEMI and NSTEMI diagnoses were determined clinically, and only those with a final discharge diagnosis (I21.0-I21.4), defined by the WHO's 10th version of International Classification of Disease (ICD-10) diagnosis codes, were included in the study. Schizophrenia was defined as having an ICD-9 code of 295 (used in 1987-1996) or an ICD-10 diagnosis code (used from 1997 and onwards) of schizophrenia (F20) or schizoaffective disorder (F25) at an outpatient visit or in-hospital admission before the index AMI event.

\section{National registries}

SWEDEHEART contains information on risk factors, medical history, cardiac procedures, treatments during hospitalisation and discharge medications. Using the unique personal identification number given to each citizen in Sweden, the SWEDEHEART registry was linked to the National Population Register and National Patient Registry to obtain further information such as date of death, schizophrenia diagnoses and other non-cardiac comorbidities. ${ }^{12}$ All personal identification numbers were replaced with an unique SWEDEHEART number to ensure anonymity.

\section{Outcomes}

The primary outcome was a 5-year composite MACE comprised all-cause mortality, rehospitalisation for AMI, hospitalisation for stroke or heart failure. The secondary outcomes were the individual components of MACE and bleeding requiring hospitalisation (fatal, cerebral or bleeding requiring surgery or transfusion, defined by ICD-9 $(430,431,432,578,285 \mathrm{~B}, 456 \mathrm{~A}, 531 \mathrm{~A}, 531 \mathrm{C}$, 531E, 531G, 532A, 532C, 532E, 532G, 533A, 533C, 533E, 533G, 534A, 534C, 534E, 534G and 569D) and ICD-10 (I60, I61, I62, D629, I850, K226, K250, K252, K254, K256, K260, K262, K264, K266, K270, K272, K274, K276, K280, K282, K284, K286, K290, K625, K920, K921 and K922) codes) at 5 years following discharge. Other investigated secondary outcomes were proportion treated with guideline recommended discharge medications, patient and system delays and length of hospital stay during hospitalisation for AMI. Length of hospital stay was measured from admission time to discharge time. Patient delay was measured as the time from symptom onset to ECG measurement, a surrogate for first medical contact and system delay was measured from first medical contact to percutaneous coronary intervention (PCI).

\section{Statistical analysis}

Continuous variables are expressed as means with SD or medians with 1st-3rd quartiles and categorical variables as counts with percentages. Differences in baseline variables between the populations were analysed using MannWhitney U tests and Student's t-test for continuous variables and $\chi^{2}$ tests for categorical variables. Time-to-event outcomes were analysed and compared using the KaplanMeier survival estimator and log-rank tests as well as univariable and multivariable Cox proportional hazard models, presented as HRs with 95\% CIs. The results are presented in four different models, the first model represents the crude HR, the second model adjusted for age and sex and the third model adjusted for age, sex, previous procedures and comorbidities (previous PCI, previous coronary artery bypass grafting (CABG), previous AMI, congestive heart failure, chronic kidney disease, chronic obstructive pulmonary disease (COPD), peripheral artery disease, previous bleeding requiring hospitalisation (defined as the bleeding outcome described earlier), stroke, diabetes, hypertension, hyperlipidaemia and smoking status). The fourth model additionally adjusted for revascularisation method during hospitalisation (PCI, CABG or medical management) and guideline recommended discharge medications (ACE-inhibitors or angiotensin II receptor blockers (ARBs), beta-blockers, statins, aspirin and P2Y12 inhibitors). Regression analyses in the final model only included hospital survivors. For the outcome MI, we used a 30-day blanking period as any early readmissions (follow-up visit or readmission) within 30 days from the index event may be incorrectly registered as a reinfarction in the database, for example, due to transfers between hospitals or coding practices. To prevent bias due to the long inclusion period and improvement of treatment over time we performed a sensitivity analysis including year of MI in the final regression model of MACE. Guideline recommended medications were additionally analysed using multiple logistic regressions 
Table 1 Baseline characteristics for all acute myocardial infarction patients with and without schizophrenia between 2000 and 2018 in Sweden

\begin{tabular}{|c|c|c|c|c|c|}
\hline & $\begin{array}{l}\text { Schizophrenia } \\
(n=1008)\end{array}$ & $\begin{array}{l}\text { Without schizophrenia } \\
(\mathrm{n}=285325)\end{array}$ & $\begin{array}{l}\text { Total } \\
(n=286333)\end{array}$ & Missing n (\%) & P value \\
\hline Age median (1st-3rd quartiles) & $64(56-71)$ & $73(63-81)$ & $71.3(12.3)$ & 0 & $<0.001$ \\
\hline Male sex, n (\%) & $652(64.7)$ & $183568(64.0)$ & $183220(64.0)$ & 0 & 0.646 \\
\hline Occupational status, $\mathrm{n}(\%)$ & & & & $58897(20.6)$ & $<0.001$ \\
\hline Working & $46(4.6)$ & $48611(17.0)$ & $48657(17.0)$ & & \\
\hline Sick leave & $102(10.1)$ & $4675(1.6)$ & $4777(1.7)$ & & \\
\hline Unemployed & $16(1.6)$ & $2988(1.1)$ & $2004(1.1)$ & & \\
\hline Retired & $574(56.9)$ & $162199(56.9)$ & $162773(56.9)$ & & \\
\hline Student/other & $12(1.2)$ & $679(0.2)$ & $691(0.2)$ & & \\
\hline Smoking status, n (\%) & & & & $25047(8.8)$ & $<0.001$ \\
\hline Never & $224(22.2)$ & $116923(41.0)$ & $117147(40.9)$ & & \\
\hline Ex-smoker (>1 month) & $184(18.3)$ & $86514(30.3)$ & $86.7(30.3)$ & & \\
\hline Smoker & $489(48.5)$ & $56953(20.0)$ & $57441(20.1)$ & & \\
\hline Diabetes, n (\%) & $394(39.1)$ & $68429(24.0)$ & $68823(24.0)$ & 0 & $<0.001$ \\
\hline Hypertension & $454(45.0)$ & $158726(55.6)$ & $159180(55.6)$ & 0 & $<0.001$ \\
\hline Hyperlipidaemia & $305(30.3)$ & $93157(32.7)$ & $93462(32.6)$ & $3786(1.3)$ & 0.062 \\
\hline Previous myocardial infarction, $\mathrm{n}(\%)$ & $250(24.8)$ & $76102(26.7)$ & $76352(26.7)$ & 0 & 0.18 \\
\hline Previous PCI, n (\%) & $79(7.8)$ & $30523(10.7)$ & $30602(10.1)$ & 0 & 0.003 \\
\hline Previous CABG, $\mathrm{n}(\%)$ & $29(2.9)$ & $20823(7.3)$ & $20852(7.3)$ & 0 & $<0.001$ \\
\hline Previous stroke, $\mathrm{n} \%$ & $126(12.5)$ & $34392(12.1)$ & $34518(12.1)$ & 0 & 0.664 \\
\hline Heart failure, n (\%) & $200(19.8)$ & $43624(15.3)$ & $43824(15.3)$ & 0 & $<0.001$ \\
\hline Chronic kidney disease, $\mathrm{n}(\%)$ & & & & $201901(70.5)$ & 0.031 \\
\hline Stage $1\left(\right.$ GFR $\left.>90 \mathrm{~mL} / \mathrm{min} / 1.73 \mathrm{~m}^{2}\right)$ & $212(21.0)$ & $67610(23.7)$ & $67822(23.7)$ & & \\
\hline Stage 2 (GFR of $60-89 \mathrm{~mL} / \mathrm{min} / 1.73 \mathrm{~m}^{2}$ ) & $43(4.3)$ & $14859(5.2)$ & $14902(5.2)$ & & \\
\hline Stage 3 (GFR of $30-59 \mathrm{~mL} / \mathrm{min} / 1.73 \mathrm{~m}^{2}$ ) & $10(1.0)$ & $1698(0.6)$ & $1708(0.6)$ & & \\
\hline COPD, n (\%) & $132(13.1)$ & $20008(7.0)$ & $20140(7.0)$ & 0 & $<0.001$ \\
\hline Previous bleeding, $\mathrm{n}(\%)$ & $74(7.3)$ & $16765(5.9)$ & $16839(5.9)$ & 0 & 0.048 \\
\hline Peripheral artery disease, $\mathrm{n}(\%)$ & $42(4.2)$ & $16799(5.9)$ & $16841(5.9)$ & 0 & 0.02 \\
\hline
\end{tabular}

CABG, coronary artery bypass graft; COPD, chronic obstructive pulmonary disease; GFR, glomerular filtration rate; PCI, percutaneous coronary intervention.

adjusting for baseline characteristics, as described in the third model. All $p$ values were two-tailed and a value $<0.05$ was considered statistically significant. Statistical analyses were performed using STATA V.14.0 and SPSS V.25.

\section{RESULTS}

\section{Baseline characteristics}

The baseline characteristics of the cohort are outlined in table 1. Patients with schizophrenia $(n=1008)$ were younger than those without schizophrenia $(n=285325)$ (median 64 vs 73 years) at the time of the AMI, less likely to be under employment and more often on sick leave (all $\mathrm{p}$ value $<0.001$ ). Patients with schizophrenia were also more often current smokers and fewer had never smoked ( $p$ value $<0.001$ ). They also had a higher prevalence of diabetes, heart failure, COPD and previous bleeding but a lower prevalence of hypertension, chronic kidney disease and peripheral artery disease. Patients with schizophrenia also had fewer previous PCI and CABG performed despite not having fewer previous myocardial infarctions.

\section{Clinical presentation}

Clinical presentation during hospitalisation for AMI are shown in tables 2 and 3. Patients with schizophrenia had higher creatinine, triglyceride and CRP levels, and lower cholesterol levels compared with the population without schizophrenia. They also had lower systolic blood pressure, higher heart rates and more often presented with dyspnoea and cardiac arrest, as opposed to chest pain which was the most common symptom in the nonschizophrenia population. Sinus rhythm as well as left and right bundle branch blocks and pathological $Q$ waves were more common in the schizophrenia population, while their ECG less often showed atrial fibrillation or flutter compared with patients without schizophrenia. 


\begin{tabular}{|c|c|c|c|c|c|}
\hline & $\begin{array}{l}\text { Schizophrenia } \\
(n=1008)\end{array}$ & $\begin{array}{l}\text { Without schizophrenia } \\
(\mathrm{n}=285325)\end{array}$ & $\begin{array}{l}\text { Total } \\
(n=286333)\end{array}$ & Missing n (\%) & $P$ value \\
\hline Creatinine $\mu \mathrm{mol} / \mathrm{L}$ mean (SD) & $103.4(87.0)$ & $97.62(62.0)$ & $97.65(62.1)$ & $58710(20.5)$ & 0.007 \\
\hline Haemoglobin g/L mean (SD) & $134.4(18.8)$ & $136.6(18.2)$ & $136.60(18.2)$ & $105031(36.7)$ & 0.002 \\
\hline Triglycerides mmol/L mean (SD) & $1.85(1.3)$ & $1.63(1.2)$ & $1.63(1.2)$ & $286333(39.7)$ & $<0.001$ \\
\hline Cholesterol mmol/L mean (SD) & $4.83(1.3)$ & $5.00(1.5)$ & $4.99(1.5)$ & $102865(36.0)$ & 0.005 \\
\hline CRP mg/L mean (SD) & $34.86(60.4)$ & $22.15(46.4)$ & $22.20(46.5)$ & $77192(27.0)$ & $<0.001$ \\
\hline \multicolumn{6}{|c|}{ Coronary marker levels ng/L mean (SD) } \\
\hline Troponin T & $45.5(283.2)$ & $52.1(496.7)$ & $52.1(496.3)$ & $11224(3.9)$ & 0.054 \\
\hline Troponin I & $20.7(39.4)$ & $24.2(135.5)$ & $24.2(135.2)$ & & \\
\hline CKMB & $99.7(130.8)$ & $111.3(197.5)$ & $111.3(197.4)$ & & \\
\hline
\end{tabular}

CKMB, creatine kinase myocardial band; CRP, C reactive protein.

Furthermore, a worse left ventricular function was seen in the schizophrenia population. During hospitalisation fewer patients with schizophrenia received a coronary angiography, PCI or CABG.

No statistical differences were seen between the populations in the patient delay; measured from symptom onset to ECG, or system delay; measured from ECG to PCI, neither for the STEMI nor NSTEMI group (table 3). Patients without schizophrenia were hospitalised for a median of 4 days (25th-75th percentiles 4-7) and patients with schizophrenia were hospitalised for a median of 5 days (25th-75th percentiles 4-7), this difference was statistically significant (table 3 ).

\section{Discharge medications}

Patients with schizophrenia were less likely to be discharged with aspirin, P2Y12 inhibitors, ACE-inhibitors / ARBs, beta blockers and statins (all p values <0.005; table 4). Following multiple logistic regression adjusting for age, sex and comorbidities (table 5), schizophrenia was independently associated with lower prescription rates of ACE-inhibitors/ARBs (OR 0.66, 95\% CI 0.47 to 0.93 ) and statins (OR $0.3,95 \%$ CI 0.25 to 52 ).

\section{Outcomes}

The clinical outcomes following AMI are shown in table 6 and figure 1. Patients with schizophrenia had higher occurrence of MACE with an unadjusted HR of 1.35 (95\% CI 1.23 to 1.47$)$. After adjustment for age and sex in model 2 the HR increased to 2.44 (95\% CI 2.23 to 2.67). Further adjustments for comorbidities in model 3 slightly decreased the HR to 2.20 (95\% CI 1.79 to 2.71 ) and additional adjustments for revascularisation method and discharge medications in the final model 4 resulted in a HR of 2.05 (95\% CI 1.63 to 2.58). The unadjusted HR for mortality in model 1 was 1.44 (95\% CI 1.31 to 1.59), after adjustments the HR in model 2 was $2.99(95 \%$ CI 2.72 to 3.29), in model 3: 2.53 (95\% CI 1.00 to 3.21 ) and in model 4: 2.38 (95\% CI 1.84 to 3.09 ), respectively.
The HR for heart failure was increased for patients with schizophrenia in all models; the unadjusted HR in model 1 was 1.25 (95\% CI 1.10 to 1.42$)$, model 2 HR $2.14(95 \%$ CI 1.88 to 2.42 ), model 3 HR 1.49 (95\% CI 1.13 to 1.98 ) and model 4HR 1.39 (95\% CI 1.04 to 1.86$)$. For reinfarction, stroke and bleeding a difference between the populations was only seen in model 2, with $\mathrm{HR}$ of 1.53 (95\% CI 1.25 to 1.89 ) for reinfarction, 1.67 (95\% CI 1.29 to 2.17 ) for stroke and 1.55 (95\% CI 1.23 to 1.95 ) for bleeding in patients with schizophrenia.

\section{Sensitivity analysis}

Additionally adjusting for inclusion year did not alter the results in the final model 3 of MACE: HR 2.08 (95\% CI 1.67 to 2.60$)$.

\section{DISCUSSION}

The primary findings of this nationwide study were as follows. Patients with schizophrenia presented approximately 10 years earlier with AMI, but had an increased absolute risk for MACE (all-cause mortality, reinfarction, stroke or heart failure), all-cause death and heart failure, within 5 years, compared with patients without schizophrenia. After adjustments for multiple confounders, patients with schizophrenia had a more than doubled risk of MACE and mortality after AMI, compared with patients without schizophrenia.

We found large outcome differences in relation to schizophrenia; after adjustments for age and sex, we found that patients with schizophrenia had an increased risk of the composite endpoint MACE and all individual endpoints. After further adjustment for comorbidities and treatment the HR remained more than double for MACE and mortality and almost one and a half times higher for heart failure. In a comparable study conducted in Denmark ${ }^{1}$ investigating MACE following acute coronary syndrome in patients with schizophrenia, the researchers found an increased risk of MACE and all-cause mortality, 
Coronary artery disease

Table 3 Clinical presentation of acute myocardial infarction in the population with and without schizophrenia

Schizophrenia $(n=1008)$

\begin{tabular}{|c|c|c|c|c|c|}
\hline & $\begin{array}{l}\text { Schizophrenia } \\
(n=1008)\end{array}$ & $\begin{array}{l}\text { Without } \\
\text { schizophrenia } \\
(\mathrm{n}=285325)\end{array}$ & $\begin{array}{l}\text { Total } \\
(n=286333)\end{array}$ & Missing n (\%) & $P$ value \\
\hline Systolic blood pressure mm Hg mean (SD) & $137.5(30.9)$ & $146.3(30.0)$ & $146.2(30.0)$ & $68244(23.8)$ & $<0.001$ \\
\hline Diastolic blood pressure mm Hg mean (SD) & $82.3(19.1)$ & $83.6(21.6)$ & $83.6(21.6)$ & 75050 (26.2) & 0.103 \\
\hline Heart rate bpm mean (SD) & $88.5(23.0)$ & $81.7(23.4)$ & $81.8(23.4)$ & $68234(23.8)$ & $<0.001$ \\
\hline Presenting symptoms, n (\%) & & & & $15216(5.3)$ & $<0.001$ \\
\hline Chest pain & $684(67.9)$ & $224910(78.8)$ & $225594(78.8)$ & & \\
\hline Dyspnoea & $109(10.8)$ & $17420(6.1)$ & $17529(6.1)$ & & \\
\hline Cardiac arrest & $20(2.0)$ & $3638(1.3)$ & $3658(1.3)$ & & \\
\hline Other & $195(19.3)$ & $39357(13.8)$ & $39552(13.8)$ & & \\
\hline Infarct type, n (\%) & & & & $3734(1.3)$ & 0.665 \\
\hline STEMI & $343(34.0)$ & $95833(33.6)$ & $96176(33.6)$ & & \\
\hline NSTEMI & $655(65.0)$ & $185768(65.1)$ & $186423(65.1)$ & & \\
\hline ECG: rhythm, n (\%) & & & & $3737(1.3)$ & $<0.001$ \\
\hline Sinus & $896(88.9)$ & $238996(83.8)$ & $239892(83.8)$ & & \\
\hline Atrial fibrillation/flutter & $72(7.1)$ & 32865 (11.5) & 32937 (11.5) & & \\
\hline Other & $40(4.0)$ & $13464(4.7)$ & $13504(4.72)$ & & \\
\hline ECG: QRS, n (\%) & & & & $46187(16.1)$ & $<0.001$ \\
\hline Normal & $534(53.0)$ & $169196(59.3)$ & $169730(59.3)$ & & \\
\hline Pacemaker & $10(1.0)$ & $4002(1.4)$ & $2013(1.4)$ & & \\
\hline LBBB & $68(6.8)$ & $18783(6.6)$ & $18851(6.6)$ & & \\
\hline RBBB & $47(4.7)$ & $10391(3.6)$ & $10438(3.7)$ & & \\
\hline Pathological Q-wave & $185(18.4)$ & $36920(13.0)$ & $37115(13.0)$ & & \\
\hline Other & $163(16.27)$ & $46023(16.1)$ & $46187(16.1)$ & & \\
\hline Left ventricular function, $\mathrm{n}(\%)$ & & & & $104452(36.5)$ & $<0.001$ \\
\hline Normal $\geq 50 \%$ & $257(25.5)$ & $98864(34.7)$ & $99121(34.6)$ & & \\
\hline Slightly decreased $40 \%-49 \%$ & $160(15.9)$ & $42118(14.8)$ & $42278(14.8)$ & & \\
\hline Moderately decreased $30 \%-39 \%$ & $127(12.6)$ & $26530(9.3)$ & $26657(9.3)$ & & \\
\hline Severely decreased $<30 \%$ & $97(9.6)$ & $13728(4.8)$ & $13825(4.8)$ & & \\
\hline CAG, n (\%) & $573(58.9)$ & $180790(63.4)$ & $181363(63.4)$ & 0 & $<0.001$ \\
\hline PCl, n (\%) & $447(44.5)$ & $141471(49.6)$ & $141918(49.6)$ & 0 & $<0.001$ \\
\hline CABG, n (\%) & $24(2.4)$ & $10206(3.6)$ & $10230(3.6)$ & 0 & 0.041 \\
\hline Angiographic findings, $\mathrm{n}(\%)$ & & & & 0 & \\
\hline Non-conclusive & $509(50.5)$ & $132599(46.5)$ & $133108(46.5)$ & & \\
\hline Normal/atheromatosis & $36(3.6)$ & $12330(4.3)$ & $12366(4.3)$ & & \\
\hline 1-vessel, non-LM & $212(21.0)$ & $62125(21.8)$ & $62337(21.8)$ & & \\
\hline 2-vessel, non-LM & $117(11.6)$ & $37811(13.3)$ & $37928(13.3)$ & & \\
\hline 3-vessel, non-LM & $103(10.2)$ & $29333(10.3)$ & $29436(10.3)$ & & \\
\hline LMD & $31(3.1)$ & $11127(3.9)$ & $11158(3.9)$ & & 0.273 \\
\hline $\begin{array}{l}\text { Length of hospital stay, median days (25th-75th } \\
\text { percentiles) }\end{array}$ & $5(3-7)$ & $4(3-7)$ & $4(3-7)$ & 0 & 0.008 \\
\hline $\begin{array}{l}\text { Patient delay*, median days (25th-75th } \\
\text { percentiles) }\end{array}$ & $3.6(1.5-8.0)$ & $3.3(1.5-7.0)$ & $3.3(1.5-7.0)$ & $200319(70.0)$ & 0.131 \\
\hline $\begin{array}{l}\text { System delay }{ }^{\dagger} \text {, median days }(25 \text { th-75th } \\
\text { percentiles) }\end{array}$ & & & & 0 & 0.988 \\
\hline STEMI & $3.1(2.1-5.3)$ & $3.1(2.1-4.8)$ & $3.1(2.1-4.8)$ & & \\
\hline NSTEMI & $25.5(6.1-48.9)$ & $25.9(7.9-47.0)$ & $25.9(7.9-47.0)$ & & \\
\hline
\end{tabular}




\section{Table 3 Continued}

*Patient delay was measured as the time from symptom onset to ECG measurement.

†System delay was measured from ECG measurement to PCl.

CABG, coronary artery bypass graft; CAG, coronary angiography; CRP, C reactive protein; LBBB, left bundle branch block; LM, left main; LMD, left main disease; NSTEMI, non-ST elevated; PCI, percutaneous coronary intervention; RBBB, right bundle branch block ; STEMI, ST-elevated myocardial infarction.

and additionally an increased risk of stroke. Nonetheless, MACE was comprised fewer variables and the adjustment models were different in the Danish study. In a systematic review ${ }^{13}$ of mortality in 37 studies found the standard mortality rate in schizophrenia to be 2.58 , which corresponds with the increased risk found in our study. A large scale meta-analysis by Correll et at investigating cardiovascular disease in patients with severe mental illness likewise corroborates the association between increased risk of heart failure and schizophrenia seen in our study.

As previously discussed, the increased risks can be attributed to multiple mechanisms, among these an increased prevalence of various comorbidities in the population with schizophrenia. Interestingly, in our study we only found increases in baseline prevalences of smoking, diabetes, heart failure, COPD and previous bleeding and a lower prevalence of hypertension. Furthermore, patients with schizophrenia more frequently demonstrated sinus rhythm and pathological Q waves on ECGs, which is in line with previous work..$^{14}$ The latter may not only be indicative of prior recognised MI but also of unrecognised MI or missed STEMI, which is further supported by the fact that patients with schizophrenia in our study more frequently presented with atypical AMI symptoms (ie, dyspnoea) rather than typical (ie, chest pain).

Results regarding comorbidities in AMI patients with schizophrenia varies as some studies show an increased prevalence of hypertension and hyperlipidaemia, ${ }^{16} 17$ and other studies show lower prevalences of hypertension and hyperlipidaemia. ${ }^{118}$ The variation may perhaps be attributed to dissimilarity in population size and inclusion criteria or under-diagnosis of somatic comorbidities. ${ }^{19}$ An alternative reason can be the lower awareness of comorbidities found in patients with schizophrenia ${ }^{20}$ which may impede care and consequently contribute to the increased MACE presented in this study. Yet another factor which could contribute is physician bias in deprioritising patients with schizophrenia during a myocardial infarction. However, in this study we found a homogeneity in system and patient delay between the populations and a longer LOS in patients with schizophrenia following myocardial infarction, ruling out these variables as contributing factors to the increased MACE. Finally, we found patients with schizophrenia to more often present with cardiac arrest, worse ventricular function during hospitalisation and they less often underwent coronary angiography, PCI and CABG during hospitalisation. Adjustment for these variables only slightly attenuated the association between schizophrenia and poor outcome, indicating that other factors remain highly influential.

Following the AMI, there were additional dissimilarities as patients with schizophrenia were less likely to receive any of the recommended guideline medications during discharge: aspirin, P2Y12 inhibitors, ACE-inhibitors/ARBs, beta blockers and statins. This was further confirmed after adjusted multiple logistic analysis which showed ACEinhibitors/ARBs and statins to be prescribed less frequently. These results are in accordance with a study by Mitchell $e t a l^{21}$ investigating prescription of medication in severe mental illness, where they presented evidence for lower than expected rates of prescription of ACE-inhibitors/ARBs, beta blockers and statins for patients with schizophrenia. A Danish study by Kugathasan $e t a t^{2}$ investigating the association between secondary preventive treatment after AMI and mortality found scarcer redeemed prescription of guideline recommended medications in a population with schizophrenia, and concluded cardioprotective treatment following AMI to be fundamental in decreasing cardiovascular mortality in this group, underlining the importance of ensuring patients receive guideline recommended medications following AMI.

\section{Clinical implication}

This study found an increase of MACE at 5 years and evidence of fewer guideline recommended prescriptions

Table 4 Recommended medications at discharge following acute myocardial infarction comparing patients with and without schizophrenia

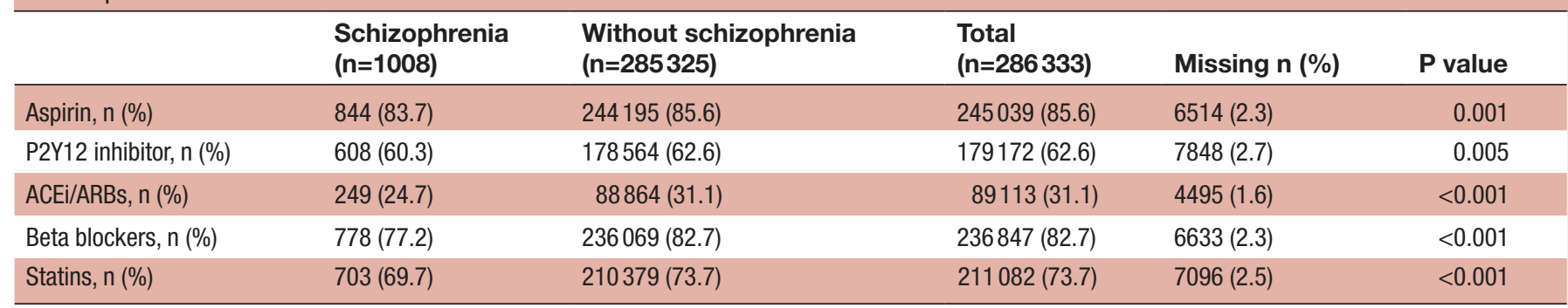

ACEi, ACE-inhibitor; ARBs, angiotensin two receptor blocker. 
Table 5 ORs of the recommended medications at discharge following acute myocardial infarction for patients with schizophrenia

\begin{tabular}{lccc}
\hline & OR $^{\star}$ & 95\% Cl & P value \\
\hline Aspirin, $\mathrm{n}(\%)$ & 0.67 & 0.41 to 1.10 & 0.11 \\
\hline P2Y12 inhibitor, $\mathrm{n}(\%)$ & 0.74 & 0.54 to 1.01 & 0.06 \\
\hline ACEi/ARBs, $\mathrm{n}(\%)$ & 0.66 & 0.47 to 0.93 & 0.02 \\
\hline Beta blockers, $\mathrm{n}(\%)$ & 0.76 & 0.53 to 1.10 & 0.14 \\
\hline Statins, $\mathrm{n}(\%)$ & 0.36 & 0.25 to 0.52 & $<0.001$ \\
\hline
\end{tabular}

*Adjusted for age, sex, smoking, comorbidities, previous coronary angiography and previous percutaneous coronary intervention.

ACEi, ACE-inhibitor; ARBs, angiotensin two receptor blocker.

following AMI. The mechanisms to why these patients experience worse outcome are many, but some may be modifiable. Improved guideline recommended treatment is essential and should not be overlooked in patients with schizophrenia. More importantly, primary preventive strategies should be introduced in early stages of these patients' lives and the authors of this study suggest a multidisciplinary approach with improved collaboration between psychiatrists, cardiologists and other involved disciplines in order to combat the poor outcome seen in this high-risk patient population.

\section{Limitations}

First, we included patients over a period of 18 years, in which both the treatment options and guideline recommendations have changed. We accounted for the possibility of time bias by adjusting for year of AMI in a sensitivity analysis, which did not alter the results. Second, the patients with schizophrenia in our study were almost 10 years younger; whether this is attributable to patient selection, that is, older patients with schizophrenia are perhaps more conservatively managed and not treated in coronary care units or catheterisation labs, thus causing an under-representation in the SWEDEHEART
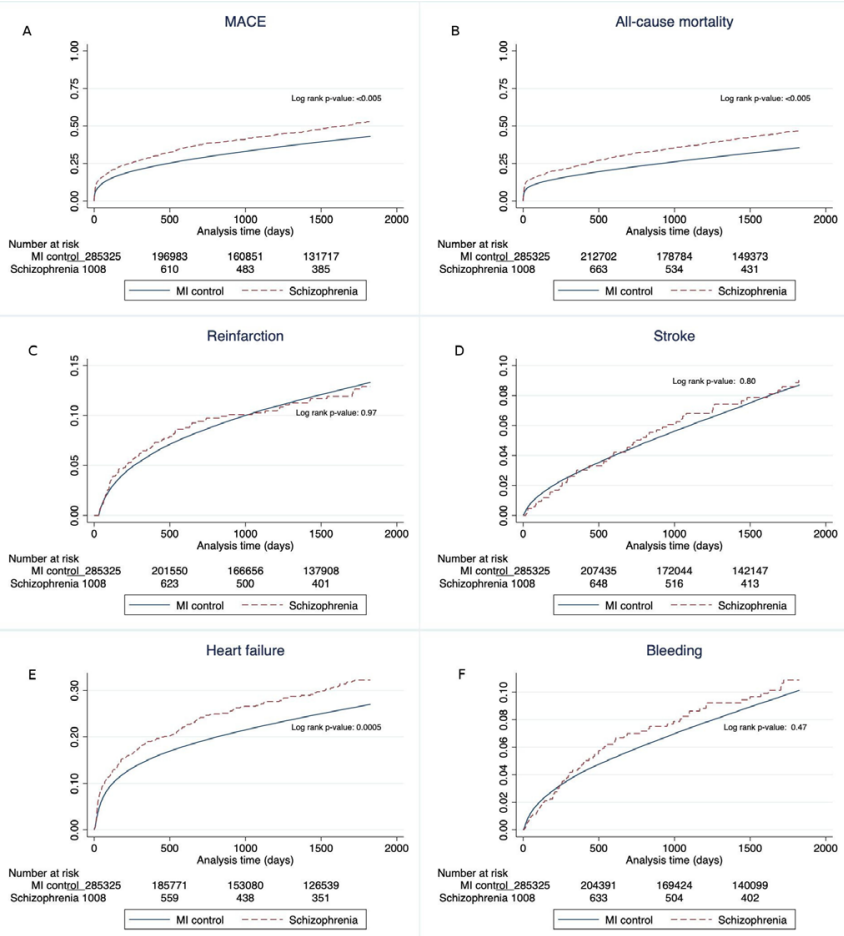

Figure 1 Kaplan-Meier survival curves showing the crude 5-year estimates following AMI of (A) MACE (all-cause mortality, rehospitalisation for AMI, hospitalisation for stroke or heart failure), (B) all-cause mortality, (C) reinfarction, (D) stroke, $(\mathrm{E})$ heart failure and $(\mathrm{F})$ bleeding comparing patients with and without schizophrenia. AMI, acute myocardial infarction; MACE, major adverse cardiac events.

registry, or a reflection of a greatly accelerated atherosclerotic cardiovascular disease process will have to be furtherly investigated in future studies. Finally, this was a register-based observational study with known inherent limitations such as risk of selection bias and confounding by indication, making causal conclusions uncertain, as well as potential underdiagnosis and misclassification of ICD-codes resulting in an

Table 6 Clinical outcomes for patients with schizophrenia following an acute myocardial infarction compared with patients without schizophrenia at 5 years

\begin{tabular}{llllc}
\hline & & \multicolumn{3}{c}{ Adjusted HR (95\% CI) } \\
\cline { 3 - 5 } & Unadjusted HR (95\% Cl) & Model 1 & Model 2 & Model 3 \\
\hline MACE & $1.35(1.23 \text { to } 1.47)^{\star}$ & $2.44(2.23 \text { to } 2.67)^{\star}$ & $2.20(1.79 \text { to } 2.72)^{\star}$ & $2.05(1.63 \text { to } 2.58)^{\star}$ \\
Mortality & $1.44(1.31 \text { to } 1.59)^{\star}$ & $2.99(2.72 \text { to } 3.29)^{\star}$ & $2.53(1.00 \text { to } 3.21)^{\star}$ & $2.38(1.84 \text { to } 3.09)^{\star}$ \\
Reinfarction & $1.00(0.82$ to 1.24$)$ & $1.53(1.25 \text { to } 1.89)^{\star}$ & $1.41(0.86$ to 2.30$)$ & $1.29(0.77$ to 2.13$)$ \\
\hline Stroke & $1.03(0.80$ to 1.34$)$ & $1.67(1.29 \text { to } 2.17)^{\star}$ & $1.72(1.00$ to 2.97$)$ & $1.72(1.00$ to 2.98$)$ \\
Heart failure & $1.25(1.10 \text { to } 1.42)^{\star}$ & $2.14(1.88 \text { to } 2.42)^{\star}$ & $1.49(1.13 \text { to } 1.98)^{\star}$ & $1.39(1.04 \text { to } 1.86)^{\star}$ \\
Bleeding & $1.09(0.86$ to 1.37$)$ & $1.55(1.23 \text { to } 1.95)^{\star}$ & $1.35(0.85$ to 2.14$)$ & $1.27(0.79$ to 2.05$)$ \\
\hline
\end{tabular}

Model 1: adjusted for age and sex.

Model 2: adjusted for age, sex, smoking, comorbidities, previous CAG and previous PCI.

Model 3: adjusted for age, sex, smoking, comorbidities, previous CAG and previous PCI, discharge medications and treatment with CAG and $\mathrm{PCl}$.

${ }^{*} \mathrm{p}<0.005$.

CAG, coronary angiography; MACE, major adverse cardiac outcome (all-cause mortality, rehospitalisation for AMI, hospitalisation for stroke or heart failure); $\mathrm{PCl}$, percutaneous coronary intervention. 
underestimated prevalence. The 30-day blanking period of MI applied to avoid misclassification of reinfarctions could further contribute to this limitation, however, not blanking the period could have incorrectly inflated reinfarction rates.

\section{CONCLUSION}

Patients with schizophrenia experienced an AMI almost 10 years earlier than patients without schizophrenia. They less often underwent invasive procedures and were less often treated with guideline recommended medications at discharge, and had more than doubled risk of MACE and allcause mortality. Improved primary and secondary preventive measures, including adherence to guideline recommendations, are warranted and may improve outcome.

Contributors RA designed the study, developed the protocol and analysis plan as well as performed the statistical analyses. RA, AW, SE, TJ, DE, CP and PA interpreted the results and provided feedback. RA wrote the first draft of the manuscript which was shaped by the critical revision of all coauthors. All authors approved the final version suitable for publication.

Funding The authors have not declared a specific grant for this research from any funding agency in the public, commercial or not-for-profit sectors.

Competing interests None declared.

Patient consent for publication Not required.

Ethics approval The study was approved by the Swedish Ethical Review Authority at Lund University. There was no patients nor public involvement in this study. No patients consent was required for publication due to anonymisation.

Provenance and peer review Not commissioned; externally peer reviewed.

Data availability statement All data relevant to the study are included in the article or uploaded as supplementary information. All patients were deidentified upon inclusion.

Open access This is an open access article distributed in accordance with the Creative Commons Attribution Non Commercial (CC BY-NC 4.0) license, which permits others to distribute, remix, adapt, build upon this work non-commercially, and license their derivative works on different terms, provided the original work is properly cited, appropriate credit is given, any changes made indicated, and the use is non-commercial. See: http://creativecommons.org/licenses/by-nc/4.0/.

ORCID iDs

Rubina Attar http://orcid.org/0000-0003-1009-4189

Pontus Andell http://orcid.org/0000-0002-2759-1379

\section{REFERENCES}

1 Attar R, Valentin JB, Freeman P, et al. The effect of schizophrenia on major adverse cardiac events, length of hospital stay, and prevalence of somatic comorbidities following acute coronary syndrome. Eur Heart J Qual Care Clin Outcomes 2019;5:121-6.

2 De Hert MA, van Winkel R, Van Eyck D, et al. Prevalence of the metabolic syndrome in patients with schizophrenia treated with antipsychotic medication. Schizophr Res 2006;83:87-93.
3 McCreadie RG, Scottish Schizophrenia Lifestyle Group. Diet, smoking and cardiovascular risk in people with schizophrenia: descriptive study. Br J Psychiatry 2003;183:534-9.

4 Hennekens $\mathrm{CH}$, Hennekens AR, Hollar D, et al. Schizophrenia and increased risks of cardiovascular disease. Am Heart $J$ 2005;150:1115-21.

5 Westman J, Eriksson SV, Gissler M, et al. Increased cardiovascular mortality in people with schizophrenia: a 24 -year national register study. Epidemiol Psychiatr Sci 2018;27:519-27.

6 Correll CU, Solmi M, Veronese N, et al. Prevalence, incidence and mortality from cardiovascular disease in patients with pooled and specific severe mental illness: a large-scale meta-analysis of $3,211,768$ patients and $113,383,368$ controls. World Psychiatry 2017:16:163-80.

7 Attar R, Berg Johansen M, Valentin JB, et al. Treatment following myocardial infarction in patients with schizophrenia. PLOS One 2017:12:e0189289.

8 Mitchell AJ, Lawrence D. Revascularisation and mortality rates following acute coronary syndromes in people with severe mental illness: comparative meta-analysis. Br J Psychiatry 2011;198:434-41.

9 Wu S-I, Chen S-C, Juang JJM, et al. Diagnostic procedures, revascularization, and inpatient mortality after acute myocardial infarction in patients with schizophrenia and bipolar disorder. Psychosom Med 2013;75:52-9.

10 Druss BG, Bradford DW, Rosenheck RA, et al. Mental disorders and use of cardiovascular procedures after myocardial infarction. JAMA 2000;283:506-11.

11 De Hert M, Detraux J, van Winkel R, et al. Metabolic and cardiovascular adverse effects associated with antipsychotic drugs. Nat Rev Endocrinol 2011;8:114-26.

12 Jernberg T, Attebring MF, Hambraeus K, et al. The Swedish websystem for enhancement and development of evidence-based care in heart disease evaluated according to recommended therapies (SWEDEHEART). Heart 2010;96:1617-21.

13 Saha S, Chant D, McGrath J. A systematic review of mortality in schizophrenia: is the differential mortality gap worsening over time? Arch Gen Psychiatry 2007;64:1123.

14 Polcwiartek C, Kragholm K, Hansen SM, et al. Electrocardiogram characteristics and their association with psychotropic drugs among patients with schizophrenia. Schizophr Bull 2020;46:354-62.

15 Nielsen J, Juel J, Alzuhairi KS, et al. Unrecognised myocardial infarction in patients with schizophrenia. Acta Neuropsychiatr 2015;27:106-12.

16 Liao C-H, Chang C-S, Wei W-C, et al. Schizophrenia patients at higher risk of diabetes, hypertension and hyperlipidemia: a population-based study. Schizophr Res 2011;126:110-6.

17 Joshi KB, Nillawar A, Thorat AP. Cardiovascular disease risk in schizophrenia patients: a case control study. J Clin Diagn Res 2013;7:2694-6.

18 Pérez-Piñar M, Mathur R, Foguet Q, et al. Cardiovascular risk factors among patients with schizophrenia, bipolar, depressive, anxiety, and personality disorders. Eur Psychiatry 2016;35:8-15.

19 Smith DJ, Langan J, McLean G, et al. Schizophrenia is associated with excess multiple physical-health comorbidities but low levels of recorded cardiovascular disease in primary care: cross-sectional study. BMJ Open 2013;3. doi:10.1136/bmjopen-2013-002808. [Epub ahead of print: 17 Apr 2013].

20 Kilbourne AM, McCarthy JF, Welsh D, et al. Recognition of cooccurring medical conditions among patients with serious mental illness. J Nerv Ment Dis 2006;194:598-602.

21 Mitchell AJ, Lord O, Malone D. Differences in the prescribing of medication for physical disorders in individuals with $V$. without mental illness: meta-analysis. Br J Psychiatry 2012;201:435-43.

22 Kugathasan P, Horsdal HT, Aagaard J, et al. Association of secondary preventive cardiovascular treatment after myocardial infarction with mortality among patients with schizophrenia. JAMA Psychiatry 2018;75:1234. 